\title{
Neurobiological Pathways Linking Acute Mental Stress to Impairments in Executive Function in Individuals with Coronary Artery Disease
}

Kasra Moazzami ${ }^{\mathrm{a}, \mathrm{b}}$, Matthew T. Wittbrodt ${ }^{\mathrm{c}}$, Bruno B. Lima ${ }^{\mathrm{a}, \mathrm{b}}$, Jeong Hwan Kim ${ }^{\mathrm{a}, \mathrm{b}}$, Zakaria Almuwaqqat $^{\mathrm{a}, \mathrm{b}}$, Amit J. Shah ${ }^{\mathrm{a}, \mathrm{b}, \mathrm{d}}$, Ihab Hajjare,f,g, Felicia C. Goldsteinn ${ }^{\mathrm{e}, \mathrm{f}}$, Allan I. Levey ${ }^{\mathrm{e}, \mathrm{f}}$, Jonathon A. Nye ${ }^{\mathrm{h}}$, J. Douglas Bremner ${ }^{\mathrm{c}, \mathrm{g}, \mathrm{h}}$, Viola Vaccarino ${ }^{\mathrm{a}, \mathrm{b}}$ and Arshed A. Quyyumi ${ }^{\mathrm{b}, *}$

${ }^{a}$ Department of Epidemiology, Rollins School of Public Health, Emory University, Atlanta, GA, USA

${ }^{\mathrm{b}}$ Emory Clinical Cardiovascular Research Institute, Department of Medicine, Division of Cardiology, Emory University School of Medicine, Atlanta, GA, USA

${ }^{\mathrm{c}}$ Department of Psychiatry and Behavioral Sciences, Emory University School of Medicine, Atlanta, GA, USA

${ }^{\mathrm{d}}$ Atlanta VA Medical Center, Decatur, GA, USA

${ }^{\mathrm{e}}$ Department of Neurology, Emory University School of Medicine, Emory University, Atlanta, GA, USA

${ }^{\mathrm{f}}$ Goizuetta Alzheimer's Disease Research Center, Emory University School of Medicine, Atlanta, GA, USA

${ }^{\mathrm{g}}$ Division of General Internal Medicine and Geriatrics, Department of Medicine, Emory University, Atlanta, GA, USA

${ }^{\mathrm{h}}$ Department of Radiology and Imaging Sciences, Emory University School of Medicine, Atlanta, GA, USA

Accepted 29 December 2020

Pre-press 16 January 2021

\begin{abstract}
.
Background: Individuals with coronary artery disease (CAD) have worse executive function compared to the general population but the mechanisms are unknown.

Objective: To investigate the role of acute mental stress (MS) on the executive function of patients with CAD.

Methods: Participants with stable CAD underwent acute MS testing with simultaneous peripheral vascular function measurements and brain imaging using high resolution-positron emission tomography. Digital pulse wave amplitude was continuously measured using peripheral artery tonometry (PAT, Itamar Inc). Stress/rest PAT ratio (sPAT) of pulse wave amplitude during MS/baseline was calculated as a measure of microvascular constriction during MS. Plasma levels of catecholamine and interleukin- 6 were assessed at baseline and after MS. Executive function was assessed both at baseline and at 2 years follow-up using the Trail Making Test parts A and B.

Results: We studied 389 individuals with brain data available for 148 participants. Of this population follow-up cognitive assessments were performed in 226 individuals (121 with brain imaging). After multivariable adjustment for baseline demographics, risk factors, and medication use, a lower sPAT, indicating greater vasoconstriction, a higher inferior frontal lobe activation with MS, and increases in norepinephrine and IL-6 levels with MS were all independently associated with greater time to complete Trail B test.
\end{abstract}

\footnotetext{
${ }^{*}$ Correspondence to: Arshed A. Quyyumi, MD, Emory Clinical Cardiovascular Research Institute, Emory University School of Medicine, 1462 Clifton Road N.E. Suite 507, Atlanta, GA 30322,
}

USA. Tel.: +1 404727 3655; Fax: +1 404712 8785; E-mail: aquy yum@emory.edu. 
Conclusion: In response to acute MS, greater peripheral vasoconstriction, higher inferior frontal lobe brain activation, and increases in the levels of norepinephrine and IL-6 are associated with worse executive function.

Keywords: Brain activation, cognitive impairment, mental stress, vasoconstriction

\section{INTRODUCTION}

Coronary artery disease (CAD) is a major cause of morbidity and mortality worldwide [1]. Individuals with CAD have worse executive functioning compared to those without CAD [2-6]. Common risk factors including smoking, advanced age, diabetes, hyperlipidemia, and hypertension do not entirely account for the risk of cognitive impairment in this population [7]. An understudied risk factor for both $\mathrm{CAD}$ and worse executive function is psychological stress. Acute mental stress (MS) induces myocardial ischemia in a subset of individuals with CAD which is associated with a doubling of future cardiovascular events compared to those who do not have myocardial ischemia induced by MS [8]. However, it is unclear if acute MS can also affect the executive function in this population. Understanding the mechanisms by which acute stress impacts executive function in patients with CAD will help unravel the mechanisms by which psychological stress contributes to worsening of executive function in this population.

We and others have previously shown that acute MS activates the prefrontal brain regions including the inferior frontal gyrus [9-11], an area that is involved in emotional regulation and stress responses $[12,13]$. This region is an important node of working memory and executive control [14]. However, whether higher activation of this area in response to acute MS is associated with worse executive functioning in the CAD population is unknown.

MS causes vasoconstriction of the coronary and peripheral vasculature, catecholamine release through activation of the sympathetic nervous system and an increase in inflammatory cytokines $[15,16]$. Stress induced peripheral vasoconstriction can be estimated from changes in the digital pulse amplitude during MS, measured using peripheral arterial tonometry (PAT) [17-20]. The magnitude of peripheral vasoconstriction during MS reflects the degree of coronary vasoconstriction [21], and is an independent predictor of future cardiovascular events in patients with CAD [15]. Finally, we have recently shown that the inferior frontal lobe is highly activated in individuals with greater peripheral vasoconstriction during MS [22]. In addition, acute MS is associated with an increase in the release of catecholamines [23], and inflammatory cytokines such as interleukin-6 into the peripheral circulation $[16,24]$. However, it is unclear whether the vasomotor responses or the magnitude of catecholamine and inflammatory responses to MS correlate with executive function.

In the current study, we sought to understand the links between vascular responses during MS, activation of the inferior frontal lobe and executive function in individuals with stable CAD. As the inferior frontal lobe is directly involved in executive function, and its activation with MS is associated with greater peripheral vasoconstriction, we hypothesized that inferior frontal lobe brain activation (exposure variable) would be associated with lower executive function and its decline (outcome variable). We also investigated whether vascular, catecholamine and inflammatory responses to MS (PAT, norepinephrine, and interleukin-6) mediate the relationship between this brain activation and worsening executive function (Fig. 1).

\section{METHODS}

\section{Study population}

The data that support the findings of our study are available from the corresponding author on reasonable request. The Mental Stress Ischemia Mechanisms and Prognosis Study (MIPS) enrolled individuals with stable CAD from Emory Universityaffiliated hospitals and clinics. Data on cognitive function and vascular studies were available for 389 individuals. A random sample of 186 were included for a brain imaging sub-study, of which data on inferior frontal lobe activation was available for 148 participants. From this cohort, 121 subjects also had a face-to-face clinic visit at 2 years of follow-up with reassessments of cognitive function. A detailed study protocol has been previously published [25]. Presence of CAD was defined based on a by an abnormal coronary angiogram showing evidence of 


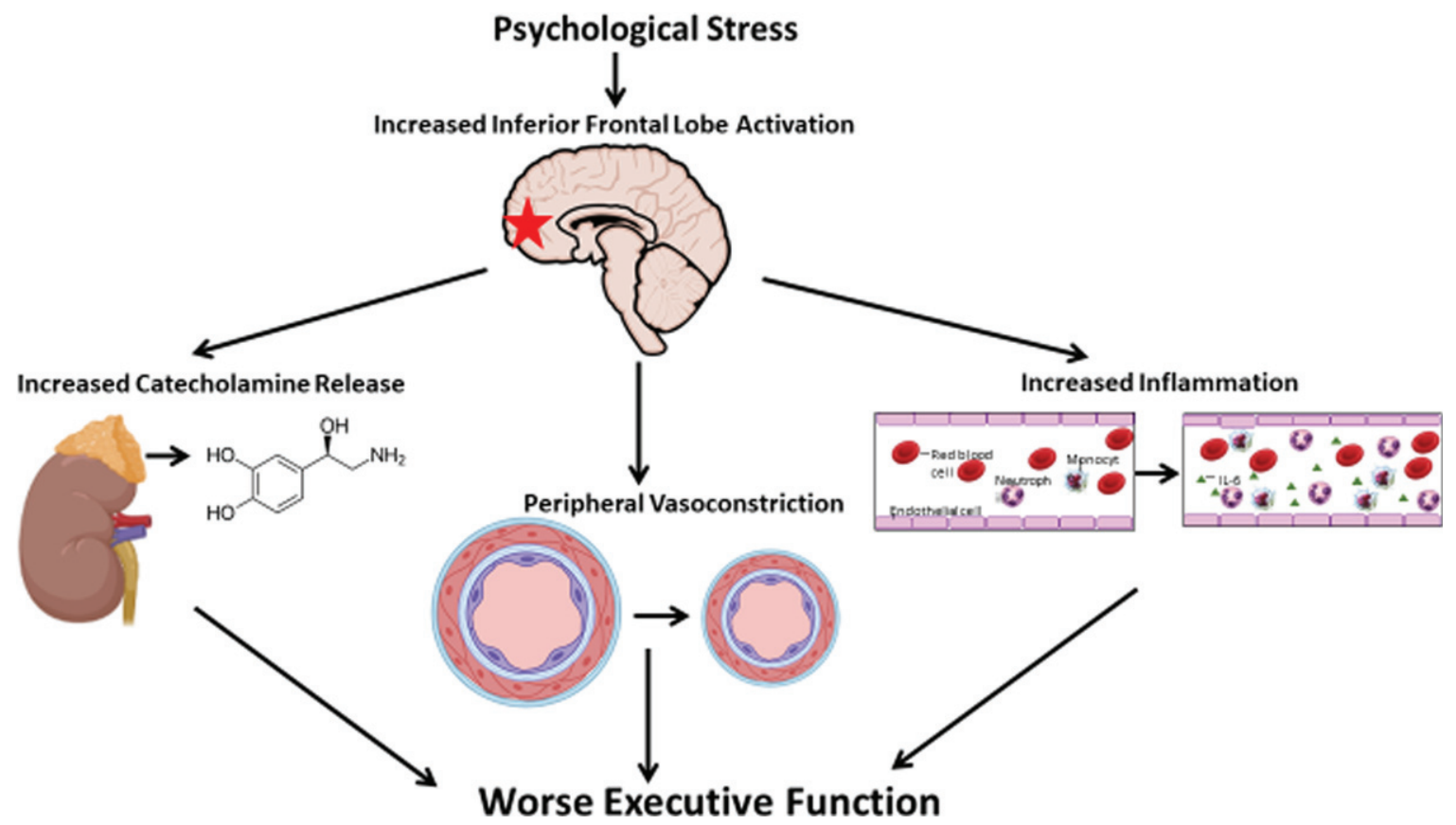

Fig. 1. A model of acute psychological stress leading to executive function impairment. Mental stress-induced inferior frontal lobe activation is directly associated with worse executive function. Greater peripheral vasoconstriction, higher norepinephrine and interleukin- 6 release to MS partly mediates the relationship between inferior frontal lobe activation and worse executive function.

atherosclerosis, a positive nuclear stress test, or a history of prior myocardial infarction or revascularization. Exclusion criteria included a history of recent (less than 1 week) acute coronary syndrome or decompensated heart failure, end-stage renal disease, systolic blood pressure $>180 \mathrm{~mm} \mathrm{Hg}$ or diastolic blood pressure $>110 \mathrm{~mm} \mathrm{Hg}$ on the day of the clinic visit, or unstable psychiatric conditions such as schizophrenia. Data regarding sociodemographic characteristics, medical history, and medication use of all participants were collected using standardized questionnaires, and clinical information was verified by medical record review. This study was approved by the Institutional Review Board of Emory University, and all participants provided informed consent.

\section{Mental stress testing}

All participants underwent MS testing using a standardized protocol, as previously described [25-27]. Briefly, following $30 \mathrm{~min}$ of resting in a temperature controlled $\left(21^{\circ} \mathrm{C}-23^{\circ} \mathrm{C}\right)$, quiet, and dimly lit room, subjects were asked to perform two control tasks (counting aloud and recalling a neutral event), followed by two mentally stressful conditions including a mental arithmetic task and a public speaking task.
During the mental arithmetic task, each participant was asked to perform a series of increasingly complicated mathematical calculations under time pressure, including addition, subtraction, multiplication, and division, whereas they received negative feedback on their performance from a staff member performing the test who was wearing a white coat [28]. The difficulty of mental math was increased until participants incorrectly answered three successive problems. During the public speaking task, each participant was given two stressful situations, one involving a longterm house guest who had overstayed her welcome and the other an uncomfortable situation in which an elderly sister was unfairly hit while driving in a parking lot. Participants were then asked to prepare a statement in $2 \mathrm{~min}$ and present it for $3 \mathrm{~min}$ for each situation and were told the speech would be evaluated for content. Blood pressure and heart rate were recorded at one-minute intervals during the control and stress tasks using an automated oscillometric device.

\section{Executive function testing}

All tests were performed on the day of MS testing and brain imaging. We administered the Trail Making 
Test part A to test visuomotor sequencing [29]. Trailmaking part $\mathrm{B}$ test was used to measure executive function [29]. During Trails A, each participant was instructed to draw lines sequentially connecting 25 encircled numbers distributed on a sheet of paper, whereas during the more complex Trails B testing, patients were asked to rapidly switch between numbers and letters. The score on each part represents the amount of time (in seconds) required to complete the task. We also calculated the difference in time between completing Trail-A and Trial-B in order to better measure executive function that is not influenced by visuomotor speed only $[30,31]$.

\section{Digital blood flow measurement via finger plethysmography}

The PAT (Itamar-Medical, Israel) device was used to measure digital arterial pulse wave amplitude continuously during rest and the MS test, as previously described $[18,19]$. The device uses a modified form of plethysmography to measure pulsatile blood volume changes (Supplementary Figure 1). The probe is applied on the index finger and applies a constant subdiastolic pressure over the distal two-thirds of the finger to prevent distal venous blood stasis, unload arterial wall tension, and stabilize the probe to reduce noise. As a result, the changes in pulsatile volume only reflect changes in digital arterial blood perfusion. Pulsatile pressure changes from the probe are registered from a pressure transducer, and then fed into a specialized software which filters, amplifies, stores, and analyzes the signal in an operator independent manner. The baseline pulse wave amplitude during rest is determined by averaging the last $3 \mathrm{~min}$ of recording that preceded the MS test. The pulse wave amplitude during the MS test is determined visually as the area of maximum vasoconstriction during the MS task (Supplementary Figure 2). The stress/rest PAT ratio (sPAT) was calculated as the ratio of the pulse wave amplitude of the digit during MS compared to the resting amplitude, where a value $<1$ signifies vasoconstriction. This method has previously been validated to reflect vasoconstriction with MS testing [15, 18, 19, 32].

\section{Catecholamine response and inflammatory biomarker}

Plasma levels of epinephrine and norepinephrine were measured at rest and $2 \mathrm{~min}$ into the MS test (EIA Kit; 2-CAT ELISA, Labor Diagnostika Nord as supplied by Rocky Mountain Scientific, Centennial, Co) [33]. In addition, levels of interleukin-6 (IL-6) were measured at rest and $90 \mathrm{~min}$ after MS by a highsensitivity assay using the MesoScale system (Meso Scale Diagnostics, Rockville, MD) with the SECTOR Imager 2400, as previously described [33]. The catecholamine and inflammatory response during acute MS was calculated as the value during MS minus the value at baseline.

\section{Brain imaging during mental stress}

High resolution-positron emission tomography (HR-PET) brain imaging was conducted using a High Resolution Research Tomograph (Siemens, Inc., Knoxville, TN), with a spatial resolution of $2 \mathrm{~mm}$ [34]. Each participant underwent a total of eight brain scans, with two scans during each of the 2 control conditions (counting aloud and recalling a neutral event) and 2 scans for each of the stress conditions (arithmetic and public speaking). Subjects were injected with $20 \mathrm{mCi}$ of O-15 water $10 \mathrm{~s}$ after the beginning of each task to assess relative cerebral blood flow. The HR-PET has a sensitivity of $1,700,000$ counts per second $(\mathrm{cps}) /(\mu \mathrm{Ci} / \mathrm{ml})$ and a spatial resolution of $2.4 \mathrm{~mm}$ in the transaxial plane. This provides higher sensitivity than conventional PET cameras.

\section{Brain imaging analyses}

Analysis of HR-PET images, including realigning, normalizing, and smoothing, was completed following established protocols using statistical parametric mapping (SPM12; www.fil.ion.ucl.ac.uk/spm/ software/spm12/) [35-37]. First, a mean intensity image was created from the eight individual scans. In the next step, each individual scan was spatially normalized to this mean, and transformed into a common anatomical space (SPM8 PET Template), followed by smoothing with a three-dimensional Gaussian filter to $5 \mathrm{~mm}$ full width half maximum, and finally, normalized to whole brain activity. HR-PET imaging analysis was completed by creating individual contrast maps to determine increased regional blood flow $($ Blood FlowNet $=$ Blood FlowMental Stress Task Blood Flow Control Task). This method has been used by previous studies to determine differences in brain activation in response to MS challenges [38-41]. Next, a custom mask limiting brain activity to the bilateral inferior frontal lobe, derived from the Automatic Anatomical Labeling atlas, was applied 
to the contrast image. Individual subject responses (delta blood-flow values from individual contrast map) were extracted from the masked contrast image and averaged across non-zero voxels. We calculated the Dice coefficient to quantify the amount of overlap between the mental arithmetic task and a public speaking task. This index was calculated as the ratio of twice the intersection of two volumes divided by the sum of the two volumes, where $A$ and $B$ are values of the two volumes to be compared (DS-Coeffs(A, $\mathrm{B})=2(\mathrm{~A} \cap \mathrm{B}) /(A+\mathrm{B}))$. Values range between 0 and 1 with a value of 1 indicating total concordance between two volumes. The data showed a Dice coefficient of 0.88 indicating an excellent overlap between the mental arithmetic and public speaking tasks

\section{Statistical analysis}

We performed linear multivariable regression models to investigate the relationship between SPAT (outcome variable), and cognitive function tests. Multivariable linear regression models were also created to examine the association between inferior frontal lobe activation (outcome variable) and executive function. All models were adjusted for a priori chosen covariates, including sociodemographic and lifestyle characteristics (age, sex, race, education, and current smoking), comorbidities (hypertension, hyperlipidemia, diabetes, obesity, previous myocardial infarction, and previous revascularization), and medication use (aspirin, statin, beta-blocker and angiotensin-converting enzyme inhibitor use). We performed three separate mediation analyses with bootstrapping (1,000 bootstrap samples and a 95\% CI) to estimate direct and indirect effects of MSinduced inferior frontal lobe activation on changes in executive function over time. We hypothesized that increases in MS induced norepinephrine, IL-6 levels and vasoconstriction (sPAT) each mediate the relationship between brain activation and worsening executive function over time using Model 4 of SPSS PROCESS macro (version 2.16.3) [42]. These mediators were found to be mutually independent when conditioned on brain activation and confounders. All other statistical analyses were done using Stata 14.0 (StataCorp LP; College Station, TX). Two-sided $p$ values $<0.05$ were used for significance testing.

\section{RESULTS}

A total of 389 individuals were included in the final analysis at baseline. From this cohort, 226
Table 1

Baseline characteristics of the study population

All Patients (389)

\begin{tabular}{lc}
\hline Demographics & $62(9)$ \\
Mean age, y (SD) & $293(75.3)$ \\
Male, N (\%) & $121(31.1)$ \\
Black race, N (\%) & $15(3)$ \\
Education, years (SD) & \\
Medical History, N (\%) & $61(15.7)$ \\
Current smoking & $318(81.7)$ \\
Obesity & $312(80.2)$ \\
Hypertension & $128(32.9)$ \\
Diabetes mellitus & $55(14.1)$ \\
History of heart failure & $141(36.2)$ \\
History of myocardial infarction & \\
Mental stress related variables & $0.73(0.32)$ \\
sPAT, Mean (SD) & \\
Medications, N (\%) & $328(84.3)$ \\
Aspirin & $291(74.8)$ \\
Beta-Blocker & $332(85.6)$ \\
Statins & $187(48.2)$ \\
Angiotensin-converting enzyme inhibitors & \\
Memory Function, mean (SD) & $42(20)$ \\
Trail-A (s) & $101(50)$ \\
Trail-B (s) &
\end{tabular}

Trail-A (minimum 15, maximum 150), Trail-B (minimum 20, maximum 300), Lower scores on the Trail-A and B tests indicate better cognitive function.

individuals had executive function reassessed at the 2-year follow-up visit. Data on inferior frontal lobe activation was available for 148 individuals of which, 121 patients also completed the 2-year follow-up cognitive assessment. At baseline, the mean age of the cohort was $62 \pm 8$ years and $293(75.3 \%)$ participants were men (Table 1). The most common comorbidity was a history of hyperlipidemia followed by obesity and hypertension (Table 1). As shown in Supplementary Table 1, there were no significant differences in the baseline, clinical characteristics, medication use, and executive function tests between the group who had follow-up tests and the baseline cohort.

\section{Determinants of executive function}

In unadjusted analyses $(\mathrm{N}=389)$, older age and Black race were associated with slower completion of the Trail-B test indicating worse executive function and statin use with better executive function (Table 2). No other clinical factors were associated with executive function.

\section{Association between executive function and mental stress-induced vasoconstriction}

A slower completion of Trail-B was associated with greater vasoconstriction (lower sPAT) in 
Table 2

Association between clinical variables (demographics, co-morbidities, mental stress related variables, and medication use) and Trail-B Test $(\mathrm{N}=389)$

\begin{tabular}{|c|c|}
\hline & Trail-B \\
\hline Demographics & B $(95 \%$ CI $)$ \\
\hline Age & $0.88(0.33,1.43)$ \\
\hline Male sex & $-9.9(-21.0,1.91)$ \\
\hline Black race & $29.25(18.8,39.6)$ \\
\hline Education, y (SD) & $1.17(-2.31,4.72)$ \\
\hline \multicolumn{2}{|l|}{ Medical History } \\
\hline Dyslipidemia & $1.30(-12.87,14.4)$ \\
\hline Current smoking & $-3.68(-10.73,3.3)$ \\
\hline Obesity & $6.09(-7.11,19.31)$ \\
\hline Hypertension & $-6.27(-18.80,6.3)$ \\
\hline Diabetes mellitus & $1.25(-9.41,11.91)$ \\
\hline History of heart failure & $-6.28(-20.67,8.0)$ \\
\hline History of myocardial infarction & $-6.27(-16.2,4.17)$ \\
\hline \multicolumn{2}{|l|}{ Mental stress related variables } \\
\hline sPAT & $-12.6(-27.24,-3.2)$ \\
\hline $\begin{array}{l}\text { Heart rate changes during mental } \\
\text { stress, bpm }\end{array}$ & $1.11(-0.21,2.31)$ \\
\hline $\begin{array}{l}\text { Blood pressure changes during MS, } \\
\mathrm{mmHg}\end{array}$ & $0.23(-0.41,0.91)$ \\
\hline $\begin{array}{l}\text { Rate-pressure product at rest, } \\
\mathrm{mmHg} \mathrm{g}^{*} \mathrm{bpm}\end{array}$ & $2.84(-0.18,5.50)$ \\
\hline $\begin{array}{l}\text { Rate-pressure product during MS, } \\
\text { mmHg*bpm }\end{array}$ & $0.01(-1.65,1.69)$ \\
\hline Norepinephrine at rest, $\mathrm{pg} / \mathrm{ml}$ & $0.17(-0.07,0.43)$ \\
\hline Norepinephrine after MS, pg/ml & $0.08(0.02,0.19)$ \\
\hline $\begin{array}{l}\text { Norepinephrine change during MS, } \\
\mathrm{pg} / \mathrm{ml}\end{array}$ & $0.01(0.003,0.23)$ \\
\hline Epinephrine at rest, $\mathrm{pg} / \mathrm{ml}$ & $0.01(-0.02,0.03)$ \\
\hline Epinephrine after MS, pg/ml & $0.02(-0.02,0.05)$ \\
\hline Epinephrine change during MS, pg/ml & $0.06(-0.07,0.19)$ \\
\hline Interleukin-6 levels at rest, $\mathrm{pg} / \mathrm{ml}$ & $-6.27(-15.2,2.62)$ \\
\hline Interleukin-6 levels after MS, pg/ml & $3.24(0.86,5.61)$ \\
\hline $\begin{array}{l}\text { Interleukin-6 levels change during } \\
\text { MS, pg/ml }\end{array}$ & $4.32(0.09,9.41)$ \\
\hline \multicolumn{2}{|l|}{ Medications, N (\%) } \\
\hline Aspirin & $-9.21(-23.2,4.09)$ \\
\hline Beta-Blocker & $9.02(-2.49,20.5)$ \\
\hline $\begin{array}{l}\text { Angiotensin-converting enzyme } \\
\text { inhibitors }\end{array}$ & $3.74(-6.23,13.7)$ \\
\hline Statins & $-16.7(-30.9,-2.5)$ \\
\hline
\end{tabular}

bivariate analysis $(\mathrm{N}=389$, Table 2$)$, an association that remained significant after adjusting for baseline demographics, clinical variables and medication use $(\mathrm{N}=389$, Table 3). Every $10 \mathrm{~s}$ longer duration for completion of Trail-B test (worse executive function) was associated with -0.12 (95\% CI $-0.21,-0.02)$ lower sPAT, signifying $12 \%$ greater vasoconstriction.

In order to understand the directionality of the association between sPAT and Trail-B scores, we assessed the association between sPAT at baseline and changes in cognitive function after 2 years of follow-up in
Table 3

Multivariable linear regression investigating the association between executive function at baseline (Trail-B score and difference between Trail-A and Trail-B) and mental stress related variables

\begin{tabular}{|c|c|}
\hline & Trail-B \\
\hline Variables* & B $(95 \%$ CI $)$ \\
\hline sPAT & $-5.31(-9.65,-0.88)$ \\
\hline $\mathrm{RPP}$ response, $\mathrm{mmHg}^{*} \mathrm{bpm}$ & $0.91(-2.89,13.32)$ \\
\hline Epinephrine response, $\mathrm{pg} / \mathrm{ml}$ & $1.68(-2.21,6.72)$ \\
\hline Norepinephrine response, $\mathrm{pg} / \mathrm{ml}$ & $2.89(1.01,7.63)$ \\
\hline Interleukin-6 response, $\mathrm{pg} / \mathrm{ml}$ & $4.69(0.25,8.71)$ \\
\hline Inferior Frontal Lobe Activation** & $11.2(1.01-21.3)$ \\
\hline
\end{tabular}

*SD units. Definition of 1 SD: sPAT 0.34, RPP response 2,997 $\mathrm{mmHg}{ }^{*} \mathrm{bpm}$, Epinephrine response $47.2 \mathrm{pg} / \mathrm{ml}$, Norepinephrine response $280.2 \mathrm{pg} / \mathrm{ml}$, Interluekin-6 response $2.01 \mathrm{pg} / \mathrm{ml}$, Inferior frontal lobe activation 1.01. ${ }^{* *}$ Analyses related to inferior frontal lobe activation was performed on 148 individuals. Model adjusted for demographics (age, sex, race, and education), clinical variables (body mass index, hyperlipidemia, diabetes mellitus, smoking history, prior myocardial infarction, and heart failure), blood pressure at baseline, and medication use (aspirin, statin, angiotensin-converting enzyme inhibitor, and beta-blockers), ratepressure product during MS.

226 participants. A lower sPAT was independently associated with slower completion of Trail-B tests over time indicating worsening executive function, after adjusting for the aforementioned covariates and baseline executive function (B $-0.03,95 \% \mathrm{CI}-0.11$, $-0.009)$.

\section{Association between executive function and mental stress-induced inferior frontal lobe activation}

As shown in Supplementary Table 2, unadjusted analyses showed significant associations between higher activation of the inferior frontal lobe with MS and worse performance in both Trail-A and Trail-B scales $(\mathrm{N}=148)$. When further adjusting for baseline demographics, clinical variables and medication use, only measures of executive function (Trail-B) remained significantly associated with inferior frontal lobe brain activation (Table 3). Every SD increase in MS-induced inferior frontal lobe activation was associated with $12.1 \mathrm{~s}$ longer duration to complete Trail-B test (B 12.1, 95\% CI 1.1-23.1).

In longitudinal analyses $(\mathrm{N}=121)$, after a 2-year follow-up, a higher inferior frontal lobe activation with MS at baseline was associated with greater time needed to complete Trail-B test after adjusting for the aforementioned covariates (B $0.24,95 \%$ CI 0.11 , 0.39 ). 


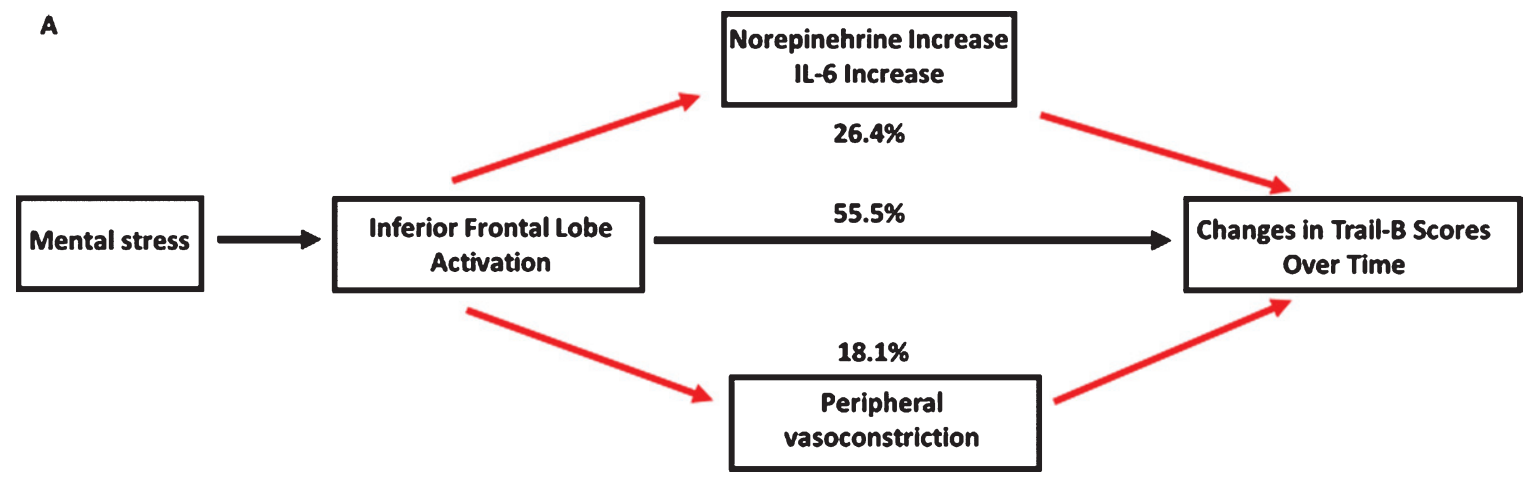

Fig. 2. Mediation analysis linking higher mental stress-induced brain activation to worse executive function. Model adjusted for demographics (age, sex, race, and education), clinical variables (body mass index, hyperlipidemia, diabetes mellitus, smoking history, prior myocardial infarction, and heart failure), baseline blood pressure levels, baseline Trail-B scores, and medication use (aspirin, statin, angiotensin-converting enzyme inhibitor, and beta-blockers). Indirect effects of norepinephrine increase, IL-6 increase, and lower sPAT on the association between inferior frontal lobe activation and change in Trail-B scores over time. Norepinephrine, Il-6, and sPAT accounted for $14.1 \%, 12.3 \%$. and $18.1 \%$ of the association (Indirect effect/Total effect $\mathrm{x} 100$ ).

\section{Association between executive function and mental stress-induced catecholamine and inflammatory responses}

Baseline levels of epinephrine, norepinephrine and IL-6 were not associated with Trail-B scores $(\mathrm{N}=389$, Table 2). However, higher levels of norepinephrine and IL-6 after MS as well as changes in these levels with MS were significantly associated with longer duration to complete the Trail-B test $(\mathrm{N}=389$, Table 1$)$, an association that remained significant after adjustment (Table 3). In longitudinal analyses $(\mathrm{N}=226)$, an increase in norepinephrine and IL-6 levels with MS were significantly associated with longer duration to complete Trail-B tests after 2-years of follow up (B 0.002, 95\% CI 0.001-0.005, and B $0.03,95 \%$ CI $0.01-0.06$, for changes in norepinephrine and IL-6 levels, respectively).

\section{Mediation analyses}

We performed mediation analyses on 121 individuals to examine the hypothesized mechanistic links between a higher level of inferior frontal lobe activation with MS, and worse executive function during follow-up. As shown in Fig. 2, these pathways significantly mediated the association between brain activation and worsening of the time needed to complete Trail-B test over time. After adjusting for the aforementioned covariates and baseline Trail-B scores, an increase in norepinephrine and IL-6 levels after MS appear to mediate the association between higher inferior frontal lobe brain activation and worsening of time needed to complete Trail-B scores during follow-up by $26.4 \%$. We also investigated a separate pathway of peripheral vasoconstriction mediating the relationship between brain activation and cognitive decline. After adjusting for the above factors, a lower SPAT mediated the association between higher inferior frontal lobe activation and worsening of the time needed to complete Trail-B by $18.1 \%$ (Fig. 2).

\section{DISCUSSION}

In patients with stable CAD, we demonstrated that a higher brain activation with MS in the inferior frontal lobe is associated with prevalent worse executive function and its decline with time. Greater peripheral vasoconstriction, higher catecholamine release, and higher inflammatory responses to acute MS were also associated with worse executive function. While the directionality of these associations could not be determined from cross-sectional analyses, follow-up data showed that the neurobiological responses to acute MS are associated with a more rapid decline in executive function over time. Finally, as shown in Fig. 1, pathway analyses showed that the relationship between inferior frontal lobe activation and worsening executive function was at least partly mediated by a higher norepinephrine and IL-6 response to MS and a higher vasoconstriction to MS. These findings provide supportive evidence for the existence of a neurobiological pathway linking acute psychological stress to worse executive function in the CAD population. 
Previous studies have shown neurophysiological links between psychological stress and cardiovascular disease risk [43]. For example, brain blood flow responses to cognitive challenges identify individuals predisposed to hypertension [44], and activation of the prefrontal cortex during stress influences heart rate variability [45]. Our results further support these findings by identifying potential neurophysiological pathways that link acute psychological stress to executive function decline in the CAD population [46-48].

We showed that the inferior frontal lobe activation in response to MS may have an upstream role in the worsening of executive function through a greater vasoconstrictor response. The inferior frontal lobe is involved in processes relevant to stress such as regulation of attention and outcome expectancies [49]. Through its connections with the parietal lobe, the inferior lobe also mediates a heightened activity in brain areas involved in perception and cognition during stress. We have recently shown that among individuals with $\mathrm{CAD}$, this region is highly activated in response to acute MS [11], and the magnitude of activation correlates with both the peripheral vasoconstriction and MS-induced myocardial ischemia [21, 22, 27]. Our current findings further expand the role of inferior frontal lobe activation with respect to cardiovascular health by demonstrating that higher activation of this region adversely affects executive function, at least partly by a greater vasoconstrictor response to stress.

Peripheral microvascular constriction measured during psychological stress has been suggested as a biomarker of cardiovascular stress vulnerability $[15,18,19]$. Our group and others have previously shown that peripheral vasoconstriction during MS, measured as SPAT, correlates closely with coronary vasomotion and myocardial ischemia [17, 18, 20, 21]. Moreover, a lower sPAT is associated with worse outcomes in patients with CAD [15]. We now demonstrate that a greater peripheral vasoconstrictor response in response to MS is associated with both worse executive function at baseline and its' greater decline.

In response to acute MS, sympathetic stimulation causes norepinephrine release and $\alpha$-adrenergic receptor activation. A maladaptive norepinephrine response to MS has previously been shown to be associated with the development of hypertension [23]. More recently, we have shown that this maladaptive catecholamine response to MS, by producing greater vasoconstriction, can contribute to adverse cardiovascular outcomes in those with CAD [15]. Release of norepinephrine is coupled with enhanced entry of oxygen and glucose into brain tissue, resulting in regional brain activation [50]. Moreover, catecholamine reactivity to MS appears to be relatively stable over time [51]. Our current findings show that a heightened norepinephrine response to MS also adversely affects cognition and in particular, executive function. Thus, it is likely that repeated MS challenges during daily life could affect an individual's cognition through heightened catecholamine responses over time.

Acute MS increases inflammation by upregulating transcription of pro-inflammatory immune response genes and increasing degranulation of inflammatory factors from leukocytes [16, 24]. We have shown that IL-6 is an early and most consistently robust marker of inflammation that is increased with acute MS [52]. It has been demonstrated that peripheral inflammation can give rise to neuroinflammation through microglial activation [53, 54]. This heightened inflammation can subsequently accelerate cognitive impairment [55]. Our results support prior findings by showing that the magnitude of increase in IL-6 in response to acute MS is directly associated with the extent of impairment in the executive function over time.

Executive function refers to higher level cognitive processes that are needed for the attainment of a specific goal. Previous studies have shown that executive function is particularly vulnerable to the effects of acute stress [56-58]. Impairment in executive functioning has also been consistently observed in patients with CAD [59-61]. An intact executive function is crucial for management of chronic diseases such as $\mathrm{CAD}$, as reduced cognitive flexibility may result in problems with regulation of one's behavior, resulting in missed appointments, inability to make diet changes, and reduced medication adherence [62, 63]. Therefore, identifying specific factors involved in the worsening of the executive function of those with CAD could help identify individuals at higher risk of cognitive impairment, who may benefit from a more aggressive treatment.

Major strengths of our study include our ability to measure both vascular reactivity and cerebral perfusion during MS. This enabled us to explore the mechanistic links between brain activation and peripheral vasoconstriction during stress and the risk of executive function impairment. Limitations include firstly, the lack of generalizability of our findings to populations without CAD. Nonetheless, this 
is an important population to study because of the high prevalence of cognitive impairment and dementia. Second, we used standardized MS testing in the laboratory setting which may not reflect real-life stress. However, our protocol offered a controlled environment where specific effects could be tested with greater precision. Other limitations include the possibility of other confounding factors or reverse causation. It should be noted that individuals with CAD may be susceptible to language difficulties. These difficulties may become more pronounced in those with cognitive impairment, which as a result, could impair their ability to perform mental arithmetic tasks. Despite these limitations, our study is strengthened by the large size of a well-characterized cohort of individuals with CAD, and its prospective design to study the risk of cognitive impairment.

In conclusion, we demonstrated that a specific brain activation pattern during acute MS, involving the inferior frontal lobe region, that is known to be associated with emotional regulation, mediates greater peripheral vasoconstriction, at least partly via higher sympathetic nervous system activation and greater inflammation, that in turn is associated with worse executive function. These findings suggest that stress-induced inferior frontal lobe activation could help risk stratify individuals at risk of cognitive impairment. Whether therapeutic interventions targeting peripheral vasomotor responses to MS will improve cognitive function requires further investigation.

\section{ACKNOWLEDGMENTS}

This work was supported by grants P01 HL101398, R01 HL109413, R01HL109413-02S1, R01HL125246, K24HL077506, K24 MH076955, UL1TR000454, KL2TR000455, K23HL127251, and T32HL130025 from the National Institutes of Health.

\section{CONFLICT OF INTEREST}

The authors have no conflict of interest to report.

\section{SUPPLEMENTARY MATERIAL}

The supplementary material is available in the electronic version of this article: https://dx.doi.org/ 10.3233/ADR-200287.

\section{REFERENCES}

[1] Virani SS, Alonso A, Benjamin EJ, Bittencourt MS, Callaway CW, Carson AP, Chamberlain AM, Chang AR, Cheng S, Delling FN, Djousse L, Elkind MSV, Ferguson JF, Fornage M, Khan SS, Kissela BM, Knutson KL, Kwan TW, Lackland DT, Lewis TT, Lichtman JH, Longenecker CT, Loop MS, Lutsey PL, Martin SS, Matsushita K, Moran AE, Mussolino ME, Perak AM, Rosamond WD, Roth GA, Sampson UKA, Satou GM, Schroeder EB, Shah SH, Shay CM, Spartano NL, Stokes A, Tirschwell DL, VanWagner LB, Tsao CW, American Heart Association Council on Epidemiology and Prevention Statistics Committee and Stroke Statistics Subcommittee (2020) Heart Disease and Stroke Statistics-2020 Update: A report from the American Heart Association. Circulation 141, e139-e596.

[2] Stefanidis KB, Askew CD, Greaves K, Summers MJ (2018) The effect of non-stroke cardiovascular disease states on risk for cognitive decline and dementia: A systematic and meta-analytic review. Neuropsychol Rev 28, 1-15.

[3] Schievink SHJ, van Boxtel MPJ, Deckers K, van Oostenbrugge RJ, Verhey FRJ, Kohler S (2017) Cognitive changes in prevalent and incident cardiovascular disease: A 12-year follow-up in the Maastricht Aging Study (MAAS). Eur Heart J, doi: 10.1093/eurheartj/ehx365

[4] Singh-Manoux A, Britton AR, Marmot M (2003) Vascular disease and cognitive function: Evidence from the Whitehall II Study. J Am Geriatr Soc 51, 1445-1450.

[5] Singh-Manoux A, Sabia S, Lajnef M, Ferrie JE, Nabi H, Britton AR, Marmot MG, Shipley MJ (2008) History of coronary heart disease and cognitive performance in midlife: The Whitehall II study. Eur Heart J 29, 2100-2107.

[6] Xie W, Zheng F, Yan L, Zhong B (2019) Cognitive decline before and after incident coronary events. J Am Coll Cardiol 73, 3041-3050.

[7] Baumgart M, Snyder HM, Carrillo MC, Fazio S, Kim H, Johns H (2015) Summary of the evidence on modifiable risk factors for cognitive decline and dementia: A populationbased perspective. Alzheimers Dement 11, 718-726.

[8] Wei J, Rooks C, Ramadan R, Shah AJ, Bremner JD, Quyyumi AA, Kutner M, Vaccarino V (2014) Meta-analysis of mental stress-induced myocardial ischemia and subsequent cardiac events in patients with coronary artery disease. Am J Cardiol 114, 187-192.

[9] Anticevic A, Repovs G, Barch DM (2010) Resisting emotional interference: Brain regions facilitating working memory performance during negative distraction. Cogn Affect Behav Neurosci 10, 159-173.

[10] Oei NY, Veer IM, Wolf OT, Spinhoven P, Rombouts SA, Elzinga BM (2012) Stress shifts brain activation towards ventral 'affective' areas during emotional distraction. Soc Cogn Affect Neurosci 7, 403-412.

[11] Wittbrodt MT, Moazzami K, Lima BB, Alam ZS, Corry D, Hammadah M, Campanella C, Ward L, Quyyumi AA, Shah AJ, Vaccarino V, Nye JA, Douglas Bremner J (2019) Early childhood trauma alters neurological responses to mental stress in patients with coronary artery disease. J Affect Disord 254, 49-58.

[12] Koch SBJ, Mars RB, Toni I, Roelofs K (2018) Emotional control, reappraised. Neurosci Biobehav Rev 95, 528-534.

[13] Dixon ML, Thiruchselvam R, Todd R, Christoff K (2017) Emotion and the prefrontal cortex: An integrative review. Psychol Bull 143, 1033-1081.

[14] Alvarez JA, Emory E (2006) Executive function and the frontal lobes: A meta-analytic review. Neuropsychol Rev 16, 17-42. 
[15] Kim JH, Almuwaqqat Z, Hammadah M, Liu C, Ko YA, Lima B, Sullivan S, Alkhoder A, Abdulbaki R, Ward L, Bremner JD, Sheps DS, Raggi P, Sun YV, Shah AJ, Vaccarino V, Quyyumi AA (2019) Peripheral vasoconstriction during mental stress and adverse cardiovascular outcomes in patients with coronary artery disease. Circ Res 125, 874-883.

[16] Goebel MU, Mills PJ, Irwin MR, Ziegler MG (2000) Interleukin-6 and tumor necrosis factor-alpha production after acute psychological stress, exercise, and infused isoproterenol: Differential effects and pathways. Psychosom Med 62, 591-598.

[17] Goor DA, Sheffy J, Schnall RP, Arditti A, Caspi A, Bragdon EE, Sheps DS (2004) Peripheral arterial tonometry: A diagnostic method for detection of myocardial ischemia induced during mental stress tests: A pilot study. Clin Cardiol 27, 137-141.

[18] Hassan M, York KM, Li H, Li Q, Lucey DG, Fillingim RB, Sheps DS (2009) Usefulness of peripheral arterial tonometry in the detection of mental stress-induced myocardial ischemia. Clin Cardiol 32, E1-6.

[19] Ramadan R, Sheps D, Esteves F, Zafari AM, Bremner JD, Vaccarino V, Quyyumi AA (2013) Myocardial ischemia during mental stress: Role of coronary artery disease burden and vasomotion. J Am Heart Assoc 2, e000321.

[20] Hammadah M, Alkhoder A, Al Mheid I, Wilmot K, Isakadze N, Abdulhadi N, Chou D, Obideen M, O'Neal WT, Sullivan S, Tahhan AS, Kelli HM, Ramadan R, Pimple P, Sandesara P, Shah AJ, Ward L, Ko YA, Sun Y, Uphoff I, Pearce B, Garcia EV, Kutner M, Bremner JD, Esteves F, Sheps DS, Raggi P, Vaccarino V, Quyyumi AA (2017) Hemodynamic, catecholamine, vasomotor and vascular responses: Determinants of myocardial ischemia during mental stress. Int $J$ Cardiol 243, 47-53.

[21] Hammadah M, Kim JH, Al Mheid I, Samman Tahhan A, Wilmot K, Ramadan R, Alkhoder A, Khayata M, Mekonnen G, Levantsevych O, Bouchi Y, Kaseer B, Choudhary F, Gafeer MM, Corrigan FE, 3rd, Shah AJ, Ward L, Kutner M, Bremner JD, Sheps DS, Raggi P, Vaccarino V, Samady H, Mavromatis K, Quyyumi AA (2018) Coronary and peripheral vasomotor responses to mental stress. J Am Heart Assoc 7, $\mathrm{e} 008532$.

[22] Shah A, Chen C, Campanella C, Kasher N, Evans S, Reiff C, Mishra S, Hammadah M, Lima BB, Wilmot K, Al Mheid I, Alkhoder A, Isakadze N, Levantsevych O, Pimple PM, Garcia EV, Wittbrodt M, Nye J, Ward L, Lewis TT, Kutner M, Raggi P, Quyyumi A, Vaccarino V, Bremner JD (2019) Brain correlates of stress-induced peripheral vasoconstriction in patients with cardiovascular disease. Psychophysiology 56, e13291.

[23] Flaa A, Eide IK, Kjeldsen SE, Rostrup M (2008) Sympathoadrenal stress reactivity is a predictor of future blood pressure: An 18-year follow-up study. Hypertension 52, 336-341.

[24] Slavich GM, Irwin MR (2014) From stress to inflammation and major depressive disorder: A social signal transduction theory of depression. Psychol Bull 140, 774-815.

[25] Hammadah M, Al Mheid I, Wilmot K, Ramadan R, Shah AJ, Sun Y, Pearce B, Garcia EV, Kutner M, Bremner JD, Esteves F, Raggi P, Sheps DS, Vaccarino V, Quyyumi AA (2017) The Mental Stress Ischemia Prognosis Study: Objectives, study design, and prevalence of inducible ischemia. Psychosom Med 79, 311-317.

[26] Sheps DS, McMahon RP, Becker L, Carney RM, Freedland KE, Cohen JD, Sheffield D, Goldberg AD, Ketterer MW,
Pepine CJ, Raczynski JM, Light K, Krantz DS, Stone PH, Knatterud GL, Kaufmann PG (2002) Mental stress-induced ischemia and all-cause mortality in patients with coronary artery disease: Results from the Psychophysiological Investigations of Myocardial Ischemia study. Circulation 105, 1780-1784.

[27] Bremner JD, Campanella C, Khan Z, Shah M, Hammadah M, Wilmot K, Al Mheid I, Lima BB, Garcia EV, Nye J, Ward L, Kutner MH, Raggi P, Pearce BD, Shah AJ, Quyyumi AA, Vaccarino V (2018) Brain correlates of mental stressinduced myocardial ischemia. Psychosom Med 80, 515-525.

[28] Bremner JD (2003) Long-term effects of childhood abuse on brain and neurobiology. Child Adolesc Psychiatr Clin N Am 12, 271-292.

[29] Filskov SB, Goldstein SG (1974) Diagnostic validity of the Halstead-Reitan neuropsychological battery. J Consult Clin Psychol 42, 382-388.

[30] Arbuthnott K, Frank J (2000) Trail making test, part B as a measure of executive control: Validation using a setswitching paradigm. J Clin Exp Neuropsychol 22, 518-528.

[31] Kortte KB, Horner MD, Windham WK (2002) The trail making test, part B: Cognitive flexibility or ability to maintain set? Appl Neuropsychol 9, 106-109.

[32] Vaccarino V, Sullivan S, Hammadah M, Wilmot K, Al Mheid I, Ramadan R, Elon L, Pimple PM, Garcia EV, Nye J, Shah AJ, Alkhoder A, Levantsevych O, Gay H, Obideen M, Huang M, Lewis TT, Bremner JD, Quyyumi AA, Raggi $P$ (2018) Mental stress-induced-myocardial ischemia in young patients with recent myocardial infarction: Sex differences and mechanisms. Circulation 137, 794-805.

[33] Sullivan S, Kelli HM, Hammadah M, Topel M, Wilmot K, Ramadan R, Pearce BD, Shah A, Lima BB, Kim JH, Hardy S, Levantsevych O, Obideen M, Kaseer B, Ward L, Kutner M, Hankus A, Ko YA, Kramer MR, Lewis TT, Bremner JD, Quyyumi A, Vaccarino V (2019) Neighborhood poverty and hemodynamic, neuroendocrine, and immune response to acute stress among patients with coronary artery disease. Psychoneuroendocrinology 100, 145-155.

[34] Weinhard K, Schmand M, Casey ME, Baker K, Bao J, Eriksson L, Jones WF, Knoess C, Lenox M, Lercher M, Luk P, Michel C, Reed JH, Richerzhagen N, Treffert J, Vollmar S, Young JW, Heiss WD, Nutt R (2000) The ECAT HRRT: Performance and first clinical application of the new high resolution research tomograph. IEEE Trans Med Imaging $\mathbf{3}$, 17/12-17/16.

[35] Wittbrodt MT, Moazzami K, Lima BB, Alam ZS, Corry D, Hammadah M, Campanella C, Ward L, Quyyumi AA, Shah AJ, Vaccarino V, Nye JA, Bremner DJ (2019) Early childhood trauma alters neurological responses to mental stress in patients with coronary artery disease. JAffect Disord 254, 49-58.

[36] Bremner JD, Vythilingam M, Vermetten E, Southwick SM, McGlashan T, Nazeer A, Khan S, Vaccarino LV, Soufer R, Garg PK, Ng CK, Staib LH, Duncan JS, Charney DS (2003) MRI and PET study of deficits in hippocampal structure and function in women with childhood sexual abuse and posttraumatic stress disorder. Am J Psychiatry 160, 924-932.

[37] Bremner JD, Narayan M, Staib LH, Southwick SM, McGlashan T, Charney DS (1999) Neural correlates of memories of childhood sexual abuse in women with and without posttraumatic stress disorder. Am J Psychiatry 156, 1787-1795.

[38] Moazzami K, Wittbrodt MT, Alkhalaf M, Lima BB, Nye JA, Mehta PK, Quyyumi AA, Vaccarino V, Bremner JD, Shah AJ (2020) Association between mental stress-induced 
inferior frontal cortex activation and angina in coronary artery disease. Circ Cardiovasc Imaging 13, e010710.

[39] Moazzami K, Wittbrodt MT, Lima BB, Nye JA, Mehta PK, Pearce BD, Almuwaqqat Z, Hammadah M, Levantsevych O, Sun YV, Raggi P, Garcia EV, Goetz M, Quyyumi AA, Bremner JD, Vaccarino V, Shah AJ (2020) Higher activation of the rostromedial prefrontal cortex during mental stress predicts major cardiovascular disease events in individuals with coronary artery disease. Circulation 142, 455-465.

[40] Wittbrodt MT, Moazzami K, Shah AJ, Lima BB, Hammadah M, Mehta PK, Quyyumi AA, Vaccarino V, Nye JA, Bremner JD (2020) Neural responses during acute mental stress are associated with angina pectoris. J Psychosom Res 134, 110110.

[41] Moazzami K, Wittbrodt MT, Lima BB, Levantsevych O, Kaseer B, Martini A, Haffar A, Nye JA, Quyyumi AA, Shah A, Vaccarino V, Bremner JD (2020) Neural correlates of stress and abdominal obesity in patients with coronary artery disease. Psychosom Med 82, 272-280.

[42] Preacher KJ, Hayes AF (2008) Asymptotic and resampling strategies for assessing and comparing indirect effects in multiple mediator models. Behav Res Methods 40, 879-891.

[43] Jennings JR, Muldoon MF, Allen B, Ginty AT, Gianaros PJ (2020) Cerebrovascular function in hypertension: Does high blood pressure make you old? Psychophysiology, doi: 10.1111/psyp. 13654

[44] Jennings JR, Heim AF, Sheu LK, Muldoon MF, Ryan C, Gach HM, Schirda C, Gianaros PJ (2017) Brain regional blood flow and working memory performance predict change in blood pressure over 2 years. Hypertension 70, 1132-1141.

[45] Wager TD, Waugh CE, Lindquist M, Noll DC, Fredrickson BL, Taylor SF (2009) Brain mediators of cardiovascular responses to social threat: Part I: Reciprocal dorsal and ventral sub-regions of the medial prefrontal cortex and heart-rate reactivity. Neuroimage 47, 821-835.

[46] Ginty AT, Kraynak TE, Fisher JP, Gianaros PJ (2017) Cardiovascular and autonomic reactivity to psychological stress: Neurophysiological substrates and links to cardiovascular disease. Auton Neurosci 207, 2-9.

[47] Gianaros PJ, Wager TD (2015) Brain-body pathways linking psychological stress and physical health. Curr Dir Psychol Sci 24, 313-321.

[48] Gianaros PJ, Jennings JR (2018) Host in the machine: A neurobiological perspective on psychological stress and cardiovascular disease. Am Psychol 73, 1031-1044.

[49] Zandbelt BB, Bloemendaal M, Neggers SF, Kahn RS, Vink M (2013) Expectations and violations: Delineating the neural network of proactive inhibitory control. Hum Brain Мapp 34, 2015-2024

[50] Bola RA, Kiyatkin EA (2018) Inflow of oxygen and glucose in brain tissue induced by intravenous norepinephrine: Relationships with central metabolic and peripheral vascular responses. J Neurophysiol 119, 499-508.
[51] Hassellund SS, Flaa A, Sandvik L, Kjeldsen SE, Rostrup M (2010) Long-term stability of cardiovascular and catecholamine responses to stress tests: An 18-year follow-up study. Hypertension 55, 131-136.

[52] Marsland AL, Walsh C, Lockwood K, John-Henderson NA (2017) The effects of acute psychological stress on circulating and stimulated inflammatory markers: A systematic review and meta-analysis. Brain Behav Immun 64, 208-219.

[53] Calcia MA, Bonsall DR, Bloomfield PS, Selvaraj S, Barichello T, Howes OD (2016) Stress and neuroinflammation: A systematic review of the effects of stress on microglia and the implications for mental illness. Psychopharmacology (Berl) 233, 1637-1650.

[54] Xie X, Luo X, Liu N, Li X, Lou F, Zheng Y, Ren Y (2017) Monocytes, microglia, and CD200-CD200R1 signaling are essential in the transmission of inflammation from the periphery to the central nervous system. J Neurochem 141, 222-235.

[55] Walker KA, Gottesman RF, Wu A, Knopman DS, Gross AL, Mosley TH, Jr., Selvin E, Windham BG (2019) Systemic inflammation during midlife and cognitive change over 20 years: The ARIC Study. Neurology 92, e1256-e1267.

[56] Schoofs D, Wolf OT, Smeets T (2009) Cold pressor stress impairs performance on working memory tasks requiring executive functions in healthy young men. Behav Neurosci 123, 1066-1075.

[57] Savulich G, Hezemans FH, van Ghesel Grothe S, Dafflon J, Schulten N, Bruhl AB, Sahakian BJ, Robbins TW (2019) Acute anxiety and autonomic arousal induced by $\mathrm{CO} 2$ inhalation impairs prefrontal executive functions in healthy humans. Transl Psychiatry 9, 296.

[58] Dang J (2017) Commentary: The effects of acute stress on core executive functions: A meta-analysis and comparison with cortisol. Front Psychol 8, 1711.

[59] Zheng L, Mack WJ, Chui HC, Heflin L, Mungas D, Reed B, DeCarli C, Weiner MW, Kramer JH (2012) Coronary artery disease is associated with cognitive decline independent of changes on magnetic resonance imaging in cognitively normal elderly adults. J Am Geriatr Soc 60, 499-504.

[60] Eggermont LH, de Boer K, Muller M, Jaschke AC, Kamp O, Scherder EJ (2012) Cardiac disease and cognitive impairment: A systematic review. Heart 98, 1334-1340.

[61] Santiago C, Herrmann N, Swardfager W, Saleem M, Oh PI, Black SE, Lanctot KL (2015) White matter microstructural integrity is associated with executive function and processing speed in older adults with coronary artery disease. $A m$ J Geriatr Psychiatry 23, 754-763.

[62] Stilley CS, Bender CM, Dunbar-Jacob J, Sereika S, Ryan CM (2010) The impact of cognitive function on medication management: Three studies. Health Psychol 29, 50-55.

[63] Naik AD, Dyer CB, Kunik ME, McCullough LB (2009) Patient autonomy for the management of chronic conditions: A two-component re-conceptualization. Am J Bioeth 9, 23-30. 